\title{
Immigration and Interculturality: Integration Models of Immigrant Students in Tunisia
}

\author{
Wafa Touihri ${ }^{1}$, \\ ${ }^{1}$ Department of Sociology, Faculty of Humanities and Social Sciences of Tunis, Tunisia.
}

\begin{tabular}{|c|c|}
\hline Article Info & Abstract \\
\hline Article history: & Purpose: The study aims to examine the integration of immigrant students \\
\hline Received: 10 April 2021 & from sub-Saharan Africa within the Tunisian system of higher education. \\
\hline Revised: 19 July 2021 & Methodology/Approach/Design: This qualitative study was carried out \\
\hline Accepted: 20 July 2021 & $\begin{array}{l}\text { among } 100 \text { students enrolled in the top three accessible multicultural } \\
\text { private Tunisian universities. To analyse the relations between native }\end{array}$ \\
\hline Keywords: & immigrant students, we have devoted second criteria forming thus two case \\
\hline Immigration, & studies: there are two groups of students (a group of 50 Tunisian students \\
\hline $\begin{array}{l}\text { Integration, } \\
\text { Functionalism, }\end{array}$ & $\begin{array}{l}\text { and another group of } 50 \text { students with different sub-Saharan African } \\
\text { nationalities. }\end{array}$ \\
\hline Interactionism, & Results: The process of integrating subjects from different yet similar \\
\hline Interculturality & $\begin{array}{l}\text { cultures, in this case, sub-Saharan African students, is an anthropological } \\
\text { process seeking to put cultural diversity at the service of an inclusive }\end{array}$ \\
\hline Paper Type : & $\begin{array}{l}\text { environment with a new cultural code. The metaphor of the bridge between } \\
\text { cultures is no longer valid; the focus is rather on the concept of the salad }\end{array}$ \\
\hline Research Article & $\begin{array}{l}\text { bowl integrating different cultures. University experience constitutes, with } \\
\text { respect to the future of students, a key element to achieve professional }\end{array}$ \\
\hline Corresponding Author: & $\begin{array}{l}\text { insertion. } \\
\text { Practical Implication: The study proposes an integration model that }\end{array}$ \\
\hline Edwin Nuvianto Al Azis & $\begin{array}{l}\text { transcends the functionalist determinist approach. It is not assimilation that } \\
\text { fuses all subjects into one neither single entity nor communitarianism that }\end{array}$ \\
\hline $\begin{array}{l}\text { Email: } \\
\text { touihri.wafe@gmail.com }\end{array}$ & $\begin{array}{l}\text { maintains ethnic barriers above mixture and unanimity. } \\
\text { Originality/Value: In this study, an intercultural sociological reflection is } \\
\text { adopted while emphasizing the multicultural nature of Tunisia. }\end{array}$ \\
\hline
\end{tabular}

\section{Introduction}

Immingration is a universal phenomenon. A reflection on this matter was induced by a curious phenomenon indicating the presence of a conspicuous 'strange body' for more than a decade composed of students coming in large numbers ${ }^{1}$ from sub-Saharan Africa for education purposes and are enrolled in Tunisian private universities. Four key factors paved the way for the emergence of a new reality through which Tunisia has today become a destination for immigrant workers (Nasraoui, 2017). This phenomenon started with relocating the African Development Bank (ADB) to Tunisia in 2003 and 2014. The second factor revolves around the measure adopted by the Tunisian authorities: removing the visa requirements for many subSaharan citizens; Ivory Coast, Senegal, Mali, Nigeria, etc.).

\footnotetext{
${ }^{1}$ According to the words of our interviewee Mr Tall Sérign, president of the UESST: Union ofSenegalese Students and Trainees in Tunisia: "Currently (in 2021), we have 8,000 students ..."
} 
Another factor contributing to the growing number of students in Nigeria is the establishment of around sixty private institutes in the three Tunisian megapoleis( Tunis, Sousse, Sfax ) within few years. These institutes, designed mainly to recruit francophone students, have facilitated the integration of sub-Saharan students in Tunisia. The third factor has to do with the civil war in Libya that provoked numerous attempts of irregular migration of sub-Saharan Africans to Italy from either the Libyan or the Tunisian coastlines. This has transformed Tunisia into "a conventional destination for migration, like other North African countries, into a country of transit to Europe, even an immigration destination for some sub-Saharan Africans" (Mazzella, 2009)

In this study, the focus is channelled towards identifying the working conditions of subSaharan Africans during their journey in Tunisia, depicting the features of migrant students from Sub-Saharan Africa, and eventually seeking to explain the challenges posed by certain ontological 'connections' from the Maghreb to Africa (Pouessel, 2012). The analysis is mainly a study of the multicultural group of migrant students during their academic journey in Tunisia. The study explores the integration and social insertion difficulties thereof, especially within the institutional and socio-cultural framework. The quiding research question is the following: What is Sub-Saharan migrant students' perception of the concept of integration and how is it experienced during their academic journey in Tunisia? The approach adopted puts forth a pathway connecting the themes of integration with the integration models.

The first objective of the study is to perceive the good management of cultural differences as a key to integrating all cultural groups into a salad bowl in which "we all coexist". It is also meant to cherish the differences and to envisage a pacific coexistence of various groups while promoting equal participation at the universities of the host country. The second objective is to enhance the attitude of tolerance and respect between different groups through an acquaintance with mutual ethno-cultural specifies intrinsically exposed to openness, diversity, and cultural varieties while renouncing dogmas and social representations of racial prejudice and stereotypes. The third objective: is to achieve interculturality emanating from a relational context with a direct focus on mixed culture as a product of the different dynamics, manipulations, and strategies adopted by students to affirm his/her identity. In short, this model endows students with a comprehensive knowledge: behavioural, cultural, to engage in the process of adaptation and change and to be acquainted with intercultural competencies. This asset would constitute a key element to achieve professional insertion.

\section{Literature Review}

The originality of this study is twofold. First, unlike the majority of previous studies on the immigration of sub-Saharan African students to Tunisia, this study is not limited to a description of "the student from sub-Saharan Africa". It rather covers the relations with the host country, as an important destination to pursue a project, and conceives of new channels of exchange between developing countries with regard to education. In this study, an intercultural sociological reflection is adopted while emphasizing the multicultural nature of the Tunisian country. The study projects Tunisia as a testing ground for ethnographic research and most importantly for modern anthropological research. Cultural integration in this study is approached as a phenomenon through while asserting that cultural difference is at the origin of an obstructed integration of immigrant students. Another facet of originality is the creation of a project of interculturality between developing countries. This project is based on a sociological diagnosis of the management of cultural differences. Such a project hinges upon the strategies and concept movement from cultural differences to cultural 
diversity and from cultures to cultural ties, from a generator of conflicts to a generator of competitiveness, from multiculturalism to a mixed culture bringing about interculturality.

The most relevant examples to our research perspective are presented in Legendre's study (2003), which focused on the impact of cultural diversity on the integration of young people in schools in the Créteil academy. Empirical research has produced a typology of the representation and evaluation of cultural differences "cultural diversity and pedagogical practices, thought and attitudes of new professors at the Creteil Academy". Research has underscored the difficulties of managing cultural differences in the pedagogical practices due to latent and perceptible ethnocentrism underlying the syllabus and school foundations and due to a lack of teacher training in what concerns this matter" ( Legendre, 2003)

In the context of a sociological intervention, in his work "what is integration?" Schnapper(2007) confirms that culture is not static, it is a product of continuous exchange and innovation. He also emphasizes the importance of the study of sociologists while inviting perception of culture as subject to manipulations, transformations that are provisional or ultimate, intentional or unconscious, individual or collective. In a way, that one recognizes the serious difficulties posed by the management of differences. (Schnapper, 2007).

According to J.Galep, interculturality would foster an understanding of the social and educational problems in relation to cultural diversity (De Morgan, 1995). Interculturality introduces thus an educational approach. It is envisioned as "an articulation, an interpenetration, rebalance, harmoniously created out of different cultural data and conduct". Interculturality is not seeking to stratify social groups; it is an attempt to establish community norms for "living together". According to J. Galep: "This concept examines, to me, most importantly, a lifestyle, a conception of the other, a form of equal relations between humans and peoples." This is what anti-ethnocentrism is about" and to acquire intercultural competences" (Cerdin, 2001)

In other words, the subject of our sociological study and analysis is a deconstruction of real facts, the reality of the integration of immigrant students from sub-Saharan Africa, and its reconstruction through placing it into a conceptual hub where the two main theories of integration and interculturality act jointly. In view of the fact that "sociology creates subjects of study out of its concepts" and that "it is necessary to rupture common-sense assumptions and to construct objects from an interpretive decision and then validate hypothesis and explanation of this reconstruction in accordance with the collected data" (Beiton, 2008).

In this study, the interpretation is divided into two phases: deconstruction and reconstruction of real facts. The first is connected to an interpretation of the functionalist paradigm as a determinist approach. The second is a deconstruction and a reconstruction in relation to an interpretation of the interactionist paradigm. Thus, two following sections are relevant to our analysis and shape the morphology of our research:

- A functionalist interpretation of the realities of integrating immigrant students phenomenon

- An interactionist approach would solve the question of the intercultural prism.

- Which discourse can be adapted to this case of study?

"Integration promotes an active social participation of men and women who are compelled to permanently live on our soil and whose cultural specificities should be accepted without prejudice" (Touraine, 1993). 
In fact, according to the functionalist interpretive model, the sociology of the social order defines integration as the assimilation, continuity, and conservation of the system. Integration, therefore, denotes a state of a social system, that is to say, an integrated society is characterized by social cohesion. According to Durkheim (1967), suicide rates are inversely proportional to the integration level of social groups that are made of individuals. Integration is therefore a shield against economic and social disorganization. Integration denotes also a state of interaction between individuals and social groups (sociability), between members sharing the norms of the society to which they belong. Integration unfolds thus as a shield against marginalization, deviance, and exclusion.

From a functionalist point of view, the approach should be based on two foundations. The first is being the role of private higher institutes as an agent of integration and socialization which ensures reproduction of a social system, continuity, the transmission and perpetuation of socio-cultural models. The objective is therefore the assimilation of immigrants to create a cohesive social body within schools. In this context, Durkheim wrote: "education consists of a methodical socialization of the young generation" (Durkheim, 1920). The second tenet is a perception of culture as an independent whole that has a function and could be transmitted by heritage via vertical socialization. According to the culturalist wave, anthropologists Ruth Benedict, Margaret Mead, Ralph Linton, and the psychology Abraham Kardiner define culture as: "The global sum of attitudes, ideas and behaviors shared by members of a society" (Savida, 2006). The emphasis is on the influence of institutes and customs on one's identity.

In this theoretical framework, the question raised is: Is the integrative function of schools assured and accomplished: in our case, the private universities integrating immigrant students from sub-Saharan Africa? Also, are the integration objectives achieved?

\section{Methodology and Procedures}

In an attempt to pinpoint focal interests in our study, the aim is to examine how foreign students face cultural differences in Tunisia. It is not a mere descriptive study or an account of static information related to nationality, institutions beliefs, practices, it is rather an analysis of surveys, pre-established testimonies by the community of students from the Tunisian private education sphere. To achieve this, we have advocated a reference to the qualitative approach to explore and attain an in-depth understanding of perceptions and representations of immigrant students in accordance with the variables in the study. For data collection, we have opted for an open survey along with an exploratory sample for qualitative analysis. Only two selection criteria remained valid: Students enrolled in the top three accessible multicultural private Tunisian universities (Time University, Ibnou Khaldoun, and the Central University). To analyse the relations between native immigrant students, we have devoted second criteria forming thus two case studies: there are two groups of students (a group of 50 Tunisian students and another group of 50 students with different sub-Saharan African nationalities).

\section{Results and Discussion}

An analysis of the collected data has emphasized a striking assertion by students of poor management of cultural differences resulting in exclusion mechanisms, and integration failure observed in private Tunisian universities. The results of the study reveal that integration difficulties and a general socio-affective claim, underpinned by feelings of 
isolation, lack of understanding within schools and the host community. This trait is also objectivated by the representations of prejudice and stereotypes.

We propose an open coding meant to conceptualize and assemble data resulting from the sum of words and phrases mentioned in surveys conducted on Tunisians (50 surveys) and on African students (50 surveys) according to "categories for representations of cultural stereotypes and prejudice at the origin of integration difficulties: Reciprocal cultural misconceptions, reciprocal cultural intolerance, and a reciprocal culture misunderstanding.

Testimonies by both sides emphasized a striking existence of reciprocal cultural falsehoods. In the study, 24 surveyed Sub-Saharans are unable to make a clear distinction between the Lebanese communities and Arab communities. They argue that "for a sub-Saharan African, an Arab is an Arab"; an Ivorian respondent has explained that "the Lebanese community has settled in sub-Saharan African for many years before Independence. This community is composed of corrupt businessmen who evade paying their income taxes and exploit their black employees." For them, there is undeniable exploitation and devaluation of human beings exercised by the Lebanese community in sub-Saharan Africa, and that one of the most outrageous aspects is that most of the crimes even those of a sexual nature (pedophilia, proxenetism) remain unpunished. Combining this with the thorny problem of Islamic extremism or terrorism, we create an ostentatious mixture of unsubstantiated groundless prejudice, with which our students are imbued even before their arrival on the Tunisian soil.

A survey of 50 Tunisians has proven that our knowledge of sub-Saharan Africa as a geographic territory and a social body is significantly limited. According to our personal experiences (participant observation), Tunisian citizens lack the requisite geographic knowledge of Africa let alone the cultural aspect. We can only admit that the broadcasted images of this part of the continent are neither laudatory nor appealing. We still keep a memory of that picture that has nowadays become trivialized, of the barefoot child, skinny with abdominal distension, wearing a loincloth, his sole and unique garment, a symbol of the starving destitute Africa bearing the burden of many years of civil war and the rampaging scourge of poverty ${ }^{2}$. Moreover, the absence of chapters devoted to this part of our continent in our curriculums since primary school is one cause for a deficient knowledge of our continent. It should be noted that many Tunisians who frequented sub-Saharan African countries do no communicated positive feedbacks especially with reference to national team defeats on South African soil in continental competitions. Football players would often render their defeats to the hostile nature of the African audience, poor accommodation. They would also give pretexts such as: "the Africans were not hospital, we have health problems due to malnourishment and to the infuriating presence of insects (mosquitoes), the referees and managers of the CAF are corrupt..." They believe that it is not an exaggeration to say that our greatest fear is the hair-raising high rates of VIH, EBOLA... contamination in Africa. Mutual cultural intolerance is perceptible in the speech of the two studied groups:

Testimonies of 45 sub-Saharan African students stress that: «Tunisians are racist. They never miss a chance to deride us. They refer to us as 'kahlouche' and when they try to sound wellmannered they would call us 'Africans', as if they were not. ». 15 students state that they were ripped off: «They never sell us products at the same price as they do with their Tunisian brothers. They would even double the price». 10other Sub-Saharans believe that Tunisians

${ }^{2}$ Image generally conveyed by international NGOs such as Unicef and FAO. 
are hypocrites. They would state facts such as: «Tunisians always ignore you. They only talk to you when they need something from you which they do not possess. » 20 students assert that Sub-Saharan Africans are victims of different types of violence: «Some of us were even bullied because they were accompanied by Tunisian ladies. »We have received collective negative echoes during our survey of opinion of Sub-Saharan Africans with regard to the project of Tunisian-Sub-Saharan interaction. They argued that: «We are capable of nothing. There is no room for cultural interactions because they are hypocrites. No one, not a single person is ever nice to us ».

On the other side, 32 Tunisian students testify to the challenges of cohabitating with SubSaharan Africans. They claims that:

"[...] weirdness of [sub-Saharan Africans] / they get mad for no reason. Brawl is an indispensable part of their everyday life! They always engage in fights even at night time. They can't keep their voices down. It is almost impossible to be their neighbour. They are our guests. Yet, the show no respect to our community. Everlastingly unsatisfied. We no longer know what to do to satisfy them. That's why we have become indifferent".

In addition, 13 other Tunisian emphasize the importance of linguistic difficulties as an impediment to socio-cultural interactions: "They do not understand our language and refuse to learn it. Some of them would misinterpret everything". According to data analysis, 7 other Tunisians have criticized the attitude and behavior of Sub-Saharan Africans. They claim that: «[ Sub-Saharans ] are boastful. Their extravagance in looks is equally verbal. They are oblivious of our country's religion, the girls do not respect our dress code. Men show contempt or even disgust to those of us who talk to their women. Strangely enough, they do no never ashamed to talk to our women. Yet, we are treated and considered racist. This statement can be corroborated by the fact that we are denied access to their nightclubs.» Our 50 Tunisian respondents have expressed their rejection of the idea of an intercultural project. They ask :«How is it possible to establish a cultural interaction with such people? They even judge our questions amiss. »

Our qualitative analysis has brought to the fore a discussion based on sociological interpretations associated with the concepts of horizontal socialization, intercultural pedagogy, and intercultural competencies.

\section{Apprehending the Intercultural}

We carried out this study mainly as an attempt to solve the problem related to integration difficulties faced by senior migrants. Efforts are channelled towards liberating these students from their isolation and withdrawal into their community along with suppressing subjective negative thoughts and deconstructing erroneous insights and falsehoods about the host community, which they transmit to fresh generations of migrants. Yet, cultural diversity remains poorly managed, subject to striking ethnocentrism. "It is the oldest of all attitudes, consisting of a pure and simple rejection of all cultural forms: moral, religious, social and aesthetic that are the most distant from those to which we are accustomed." (Lévi-Strauss, 1998) It is a denial of the existence of other cultures that are different and according to him "on either side, never on even grounds". It is important to highlight the emergence of a culture that has been built throughout the years generating an ideological shift from demonstrating prejudice and stereotypes characteristic of an obsolete static culture that is interiorized and transmitted by means of a « vertical socialization» from «father" (père) to « 
pair » to a culturality product of « horizontal socialization » from « pair » to « pair » among youth (age range 20-25 years).

In other words, this new vision no longer conceives of culture as a transmitted heritage, it is rather constructed thanks to plural socialization of individuals. The theory of collective or horizontal socialization takes into consideration the impact of the processes of identification and compliance with peer norms (Galland, 2011).

This horizontal socialization between students is tinkering with other cultures. In this context, the notion of "culturality" seems relevant as it emphasizes the instrumental function of culture at the detriment of its ontological dimension and highlights tinkering, mending and strategies. Thus, we are face-to-face with a polychrome, unstable fickle reality. That's why, it has become increasingly difficult to define the identity of students in terms of culture, ethnicity, or even nationality. The conventional markers for identification (name, age, nationality, culture, social status etc. ) are no longer pertinent nor capable of identifying others let alone categorizing them. Pretceille (1996) contends that studying cultural signs involves complex operations that surpass simple decoding of pre-established signs because signs are texts and not merely simple units. That's why cultural signs that are prone to multiple articulations are often untranslatable and cannot be subject to a comprehensive interpretation.

Otherwise, a transition from the concept of cultural difference to the concept of cultural diversity. Differences not designed to allocate a set of identities, it rather serves to identify. It is an endeavour to prove the existence of a cultural mixture. On the other hand, difference abides by criteria of variations, change, and cultural dynamics of the students in questions. It is "what anthropologists refer to as a blended, creolized, crossbreed culture. This analysis could produce another definition of culture within a space of relations, a praxis, therefore a new approach that of interculturality. Our intercultural project hinges upon the effective management of cultural diversity. Envisaging routes of cultural interaction to move from a canalization of cultural differences to mutual exchange and enrichment of cultural diversity to benefit from intercultural competencies.

As a way to test the accuracy of the concept of interculturality in the realm of Tunisian Higher Institutes and socio-cultural environment thereof, we propose an open coding able to conceptualize and assemble collected data, words, and sentences provided by our respondents, in accordance with two approaches of cultural interaction: intercultural pedagogy and intercultural competences.

Intercultural pedagogy is the first strategic action plan to adopt with the view of achieving optimal management of academic cross-cultural differences. Thought-provoking, through which a student can better understand what is happening in the group to which he/she belongs, forge his/her cultural identity amid recognition and acceptance of diversity and take action to improve his living conditions (Castaño \& Martínez, 2002)

School, therefore, plays a major role in connecting all actors involved in this cultural diversity, almost in every form of expression and interaction. Consequently, different cultures have to be highlighted as "an apparatus made of symbolic systems chiefly involving language, marital laws, economic laws, art, science and religion" to "miscegenate" differences and to create an intercultural space. The following quote by Geoffroy (2001) is an illustration of the different elements defining the skills of teachers that play the role of intercultural mediators. It also unfolds as a recognition of their intercultural competencies 
that develops through a threefold process: phase one the phase of curiosity and surprise. The second is characterized by acknowledgment and appreciation of differences and the final phase allows access for mediation ». In the report provided by UNESCO and by the international commission on education, presided by Jacques Delors, entitled «Education, is a hidden treasure. The authors examine the four pillars of education: Learning to know, learning to act, learning to live together, and with others, learning to be. (Geoffrey, 2001)

Students who took lessons using intercultural pedagogy show more tendency to develop intercultural competencies and professional attributes. Being acquainted with an attitude, and intercultural competence creates channels of communication, mutual understanding, tolerance and acceptance of diversity. Intercultural competence is acquired through a threefold process: decentration, discovery, and negotiation. Decentration is "Learning to live together and with others" is the core competency that all teachers should acquire. Teachers should engage in a process of reflection, analysis of their knowledge, and teaching capacity. Students who will be future teachers should also develop this competence.

Discovery is developing a comprehensive knowledge of what has been mentioned. The first source of knowledge is the family itself. That's how one becomes able to put oneself in others' shoes to better understand their point of view. Finally, cultural negotiation is according to Cohen-Emerique (1996), a symbiosis meant to promote understanding while avoiding confrontation.

In short, according to the testimonies provided by students and in the framework of an evaluation of the implementation of an intercultural project in Tunisian private multicultural university $^{3}$, they appreciated the sociologist's endeavors and the intercultural intervention in a Tunisian private university stating that: "students often have recourse to our sociologist's office [...]" ${ }^{4}$. They have equally experienced an improvement in terms of academic skills and have shown interest in learning after receiving courses performed using intercultural pedagogy. Students testify to the efficiency of such pedagogy saying that « lectures have become more interesting with the method of convening students, of different nationalities, in a workshop for practical work and experimental observations allowing for a fusion and mixture of different cognitive styles, trying to derive the best out of each style, as a way to assert one as a dominant style" 5 . Moreover, even graduates among our surveyed group have acquired intercultural competencies during their university studies which was key to their rewarding internships and which helped them succeed in their pre-screening interviews within multinational organizations working on projects of south-south sustainable development.

Having been exposed to diversity, students have now learnt to observe and ask the right questions while maintaining the right pitch and manners. By now, they have also learned to withdraw when needed. Students become thus open to collaboration on the personal and professional levels, cognizant of the impossibility of living in social withdrawal and of ignoring their immediate environment. Their adaptation capacity is increasingly faster along

\footnotetext{
${ }^{3}$ Personal experience: head of listening unit at Time University between 2010 and 2018.

${ }^{4}$ A testimony from Awa Traore, graduated in HRM 2017 on the work of a listening cell headed by a sociologist at the Tunisian private school Time university.

${ }^{5} \mathrm{Hamza}$ Bel Haj Ali graduated in 2018 telecom network engineer at the Tunisian private higher school Time university. Currently recruited as: IT manager at the multinational Air Liquide
} 
with conduct that guarantees operational continuity. In short, they impart a valuable asset to teamwork. ${ }^{6}$

\section{Conclusion and Suggestion}

The study aimed to examine the integration of immigrant students from sub-Saharan Africa within the Tunisian system of higher education. Based on the analysis of results, it is concluded that integration and interculturality are two concepts pertaining to a broad subject of research that invokes and questions culture, identity, ethnicity, diversity, multiculturalism, pedagogy. This study on cultural diversity among migrant students in private Tunisia schools is just an investigation, through which we could relatively test theoretical propositions concerning migration, interculturality and integration and support our original hypothesis: the intercultural promotes the socio-cultural integration of the migrant students from sub-Saharan Africa during their academic journey in Tunisia. Initially, our scope of the study has observed instances of intolerance among students generating exclusion mechanism as well as a failure in the process of integrating migrant student in private Tunisian institutes. Hence, a sociological follow-up study for optimal conduct and remediation of a poorly-managed multicultural context is suggested. To manage interculturality, it is imperative to combat the social scourges that jeopardize the 'living together' project. The present study sought to decipher the complexity of the cultural shock which Tunisian and sub-Saharan African migrant students experience within the academic sphere and to devise proper maneuverings of the question of managing cultural differences. The analysis of data reveals that Intercultural competences promote the concretization of live-together projects. Nonetheless, ideas should also be coupled with action, which should be performed at three levels: building common projects, assuming shared responsibilities, forging common identities. These are the conditions for a win-win strategy, and hereby communities would undoubtedly recognize the conditions of 'living together'.

\section{Conflict of Interest}

The author declares no conflict of interest.

\section{Funding}

The study was not funded by any institution/ university.

\section{References}

Beitone, A. (2018). Economy, sociology and history of the contemporary world. Paris. Armand Colin. 69-101.Castaño, G. Martínez, G. (2002). Immigration, éducation et interculturalité. Migrance, (21).182-198.

Cohen-Emerique, M. (1980). Basic Elements for Training in the Approach to Migrants and More Generally in the Intercultural Approach. Annales de Vaucresson, (17).

Cohen-Emerique, M.(1996). The Intercultural Approach, a Prevention to the Exclusion. Les Cahiers de l'Actif, 250-251.

6 A testimony from an HR manager in "Poulina", 2016 graduate from the Tunisian private higher school Time university. 
Demorgon, J. (1995). Intercultural Relations and Learning, Paris. Armand Colin.

Demorgon, J. (2002).The Intercultural History of Societies. Economica.

Demorgon, J. Wulf, C.Müller, B. K. ( 2002), On bi-trial and multilateral exchanges in

Europe, Office franco-allemand de la jeunesse.

Durkheim, E.(1967). Suicide. Paris. University Press of France. 463.

Galland, O. (2011). Sociology of Youth.. Paris. Armand Colin.101-118.

Giddens, A. (1987). The Constitution of Society -La constitution de la société :Eléments de la théorie de la structuration. translated by Michel Audet.Paris. PUF.

Geoffroy, C. (2001). The Cordial Disagreement. Paris. Grasset,.Le Monde.45-56.

Legendre,F. (2002). Cultural diversity and pedagogy: Opinions and attitudes of the IUFM trainees of the Academy of Créteil.in Ville-Ecole-Intégration.

Levis-Strauss, C. (1989). Race History. Paris. Gallimard, collection Folio essais. 130-142.

Mazzella, S. (2009), African students in private universities in Tunisia .in Mazzella, S .(dir. ), student globalization. Le Maghreb entre Nord etSud. Paris.IRMC - Karthala.

Mesure, M.Savidan, S. (2006). The dictionary of the human sciences. Paris. PUF. Collection Quadrige.

Nasraoui, M. (2017). Sub-Saharan migrant workers in Tunisia face legislative restrictions on the employment of foreigners. European Journal of Migration. Revue Européenne des Migrations Internationales. 33. (4), 156-178.

Pouessel, S (dir. ). (2012). Blacks in the Maghreb. Enjeuxidentitaires. Paris. IRMC Karthala.

Preteceille, M. (2003).Train and educate in a heterogeneous context: for a humanism of the diverse, (Intercultural Exploration and Social Science). Paris,.Anthropos.

Pretceille, M.. (2007). Intercultural Relations and Learning. Paris. Armand Colin.

Pretceille, M.. (1992), What school for what integration?. Paris. CNDP. Hachette Education.

Pretceille,,M. Porcher,L.(1996). For another paradigm of culture: from culture to culturality, to put an end to "Babel".Education and intercultural communication. Paris. PUF.192.

Pretceille, M.(1996).Education and Intercultural Communication, Paris, PUF.

Redfield, R. Linton. R, Melville, J. (1936), Memorandum for the study of acculturation, In Américan Anthropologist.

Touraine, A. (1995). Can we live together? ,Paris, Fayard, 1997.

Touraine, A. (1993). French-style integration. Rapport du Haut Comité à l'Intégration.2 3-24.

Schanapper, D, (2007). What is integration?Paris.Gallimard. 